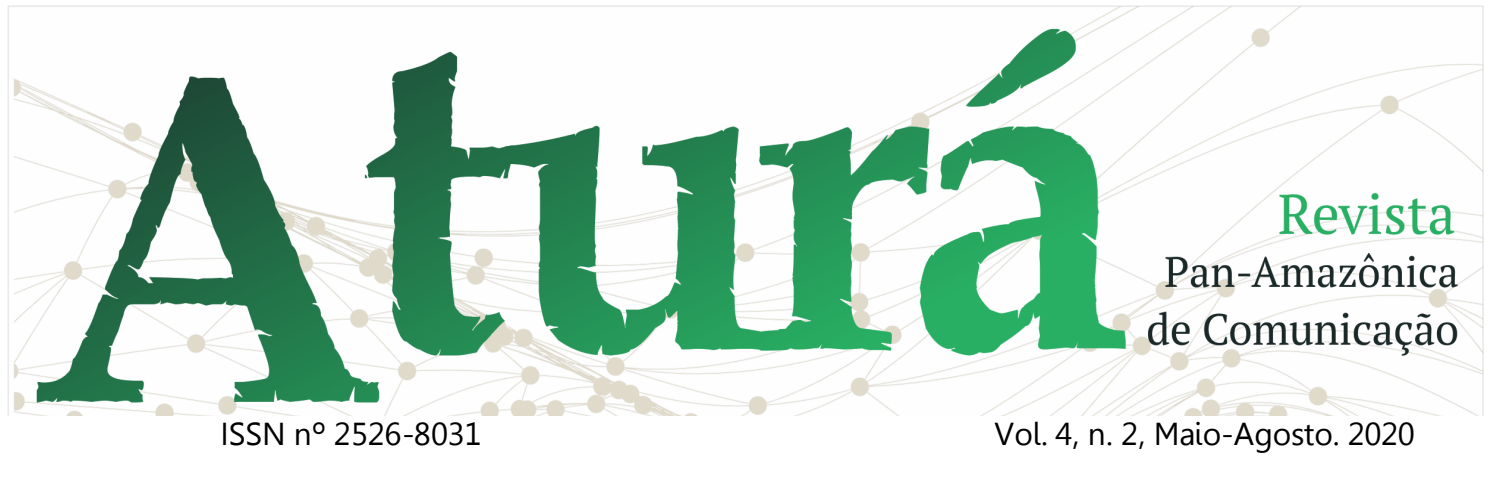

DOI: http://dx.doi.org/10.20873/uft.2526-8031.2020v4n2p242

\title{
COMUNIDADES VIRTUAIS OU CIBERCOMUNIDADES? Por uma outra visada sobre o tema
}

Virtual communities or cyber communities? For another view on the topic

¿Comunidades virtuales o cibercomunidades? Para otra vista sobre el tema

Antonio Carlos de Oliveira Carvalhal ${ }^{1}$

\section{RESUMO}

O artigo busca fazer uma análise das comunidades alocadas no ciberespaço conhecidas como comunidades virtuais, baseando-se no conceito de virtualidade de Pierre Lévy. 0 trabalho faz uma discussão sobre o que são essas comunidades virtuais através de um resgate de conceitos de comunidade elaborados na modernidade, até chegar aos conceitos contemporâneos sobre o tema, para depois analisarmos esses conceitos no ciberespaço. O objetivo do trabalho é fazer uma reflexão acerca do conceito de "comunidade virtual", tendo em vista a imensa gama de interpretações que o termo possui, e que é utilizado de diversas maneiras para especificar diferentes formas de sociabilidade na rede. Assim, faz-se uma proposta de análise tanto sobre a palavra como seu uso nos estudos da cibercultura. Com isso, pretende-se então aclarar abordagens dentro da ideia de comunidade virtual, visando um melhor entendimento e valorização do conceito enquanto auxílio indispensável para um estudo desses locais de interação dentro do ciberespaço, assim como o entendimento do que é uma comunidade para os estudos da cibercultura.

PALAVRAS-CHAVE: Virtual; Pós-modernidade; Comunidade; Comunidade Virtual; Cibercomunidades.

\footnotetext{
ABSTRACT

The article seeks to analyze the communities allocated in cyberspace known as virtual communities, based on Pierre Lévy's concept of virtuality. The work discusses what these virtual communities are through a rescue of community concepts elaborated in modern times, until reaching contemporary concepts on the subject, and then we analyze these

${ }^{1}$ Bacharel em Jornalismo pela Universidade Católica de Pelotas, UCPEL; Mestre em Comunicação Social (PUCRS).
} 


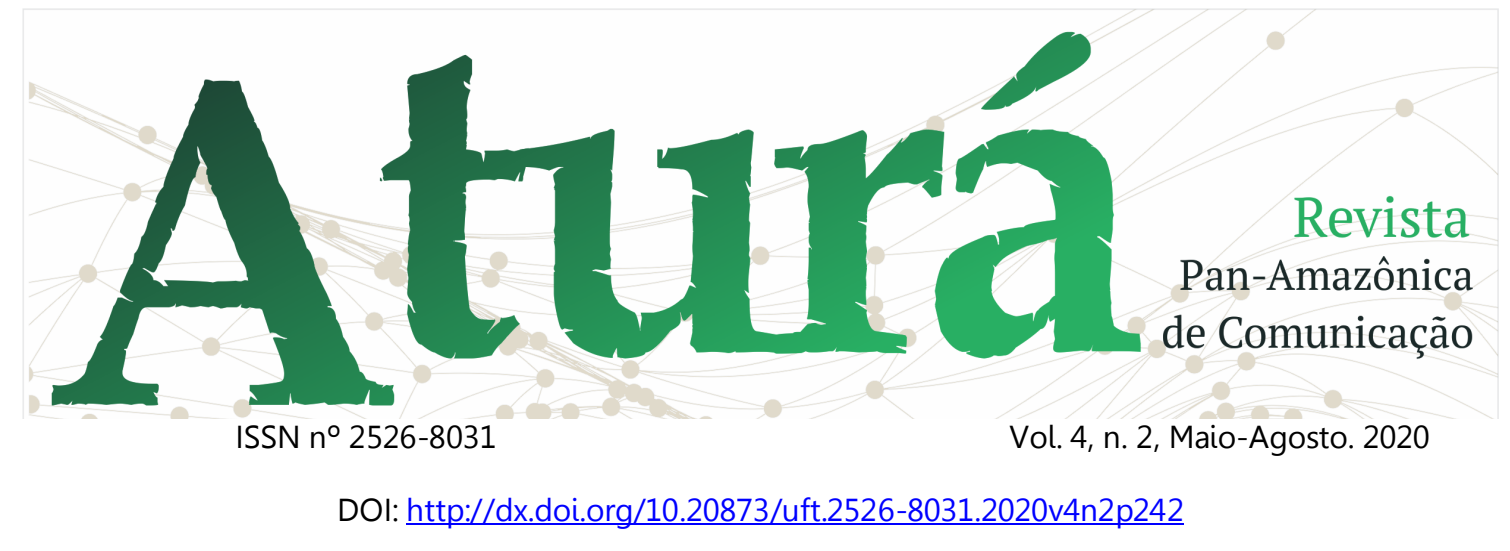

concepts in cyberspace. The objective of the work is to reflect on the concept of "virtual community", in view of the immense range of interpretations that the term has, and which is used in different ways to specify different forms of sociability in the network. Thus, an analysis proposal is made both on the word and its use in the studies of cyberculture. With that, it is intended to clarify some gaps within the idea of virtual community, aiming at a better understanding and valorization of the concept as an indispensable aid for a study of these places of interaction within cyberspace, as well as the understanding of what a community is for cyberculture studies.

KEYWORDS: Virtual; Post-Modernity; Community; Virtual communities; Cybercommunities.

\section{RESUMEN}

El artículo busca analizar las comunidades ubicadas en el ciberespacio conocidas como comunidades virtuales, a partir del concepto de virtualidad de Pierre Lévy. El trabajo hace una discusión sobre lo que son estas comunidades virtuales a través de un rescate de conceptos de comunidad elaborados en la modernidad, hasta llegar a los conceptos contemporáneos sobre el tema, para luego analizar estos conceptos en el ciberespacio. El objetivo del trabajo es reflexionar sobre el concepto de "comunidad virtual", ante el inmenso abanico de interpretaciones que tiene el término, y que se utiliza de diferentes formas para concretar distintas formas de sociabilidad en la red. Así, se realiza una propuesta de análisis tanto sobre la palabra como sobre su uso en los estudios de cibercultura. Con ello, se pretende aclarar enfoques dentro de la idea de comunidad virtual, buscando una mejor comprensión y valorización del concepto como una ayuda indispensable para el estudio de estos lugares de interacción dentro del ciberespacio, así como la comprensión de lo que es una comunidad para los estudios. cibercultura.

PALABRAS CLAVE: Virtual; Posmodernidad; Comunidad; Comunidad virtual; Cibercomunidades.

Recebido em: 12.02.2020. Aceito em: 14.04.2020. Publicado em: 01.05.2020. 


\section{A \\ ISSN n $2526-8031$ \\ Vol. 4, n. 2, Maio-Agosto. 2020 \\ Revista \\ Pan-Amazônica \\ de Comunicação \\ DOI: http://dx.doi.org/10.20873/uft.2526-8031.2020v4n2p242}

\section{Introdução}

A partir da década de 1950 o mundo passou por várias transformações sociais, políticas, econômicas e principalmente tecnológicas, que mudaram totalmente a de sociedade. Os efeitos dessas mudanças ainda estão sendo estudados no intuito de compreender seu impacto no mundo contemporâneo. Um desses estudos é sobre uma nova cultura que nasce das relações apoiadas pela rede mundial de computadores, a cibercultura. A cibercultura traz consigo uma característica que nos abre imensas possibilidades de discussão acerca das interpretações e novas formas de relacionamento: a virtualidade.

Assim, o trabalho busca debater o que é uma comunidade virtual, passando por uma revisão dos principais conceitos de comunidade até chegar à discussão sobre o que seriam então essas "cibercomunidades". O termo comunidade virtual possui uma imensa gama de interpretações que acarretam na perda do entendimento do que realmente é o objeto do qual ele trata. Baseado nisso, faz-se uma reflexão sobre os conceitos de o que é uma comunidade, o que é o virtual e, posteriormente, $\circ$ que 0 termo "comunidade virtual", utilizado de forma corrente, possui de cerne de estudo.

\section{O que é o Virtual?}

Para definir o que é o virtual, Lévy parte de uma distinção sobre três sentidos que a palavra comporta: o corrente, ligado a um entendimento comum da palavra, o filosófico e, por fim, o técnico, ligado à informática. $O$ sentido corrente é o de se confundir virtualidade com irrealidade, com inexistência. Então, o virtual seria algo inexistente, não real. 0 sentido filosófico é de que o virtual existe em potência, força, e não em ato, onde a realização dessa potência só se daria através de uma atualização. Para melhor compreender o conceito, faz-se 


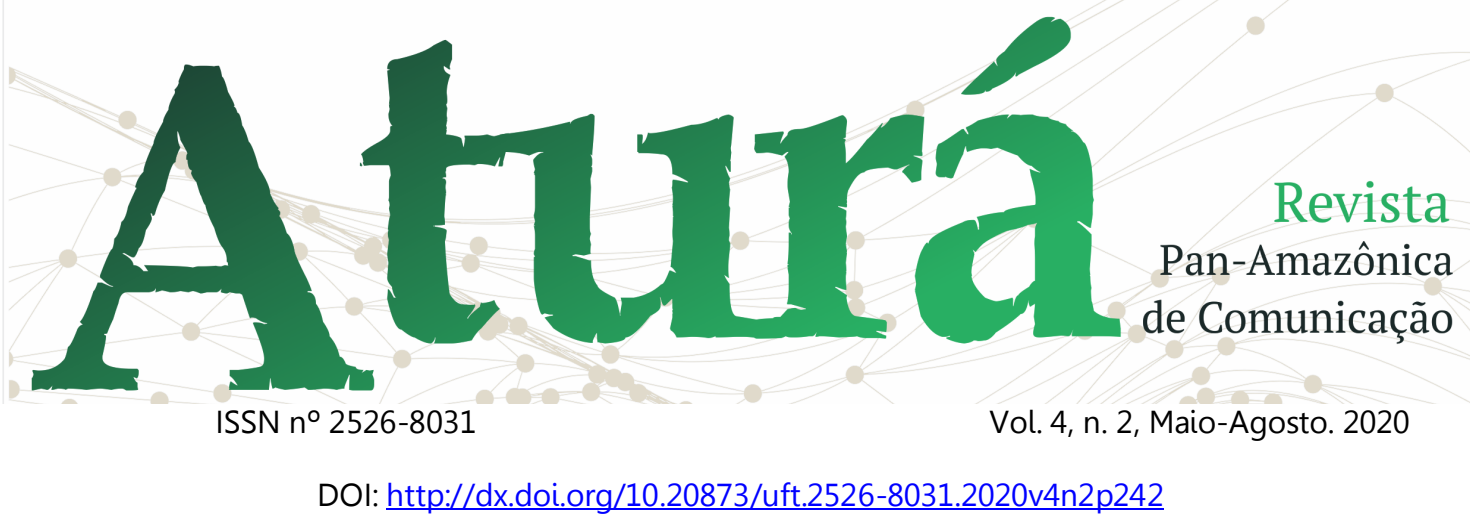

necessário uma breve apresentação das diferenças entre virtual e possível para se ter bem claro o que significa cada um dos termos.

O possível já está constituído, mas permanece oculto. Ele se realizará sem que nada mude em sua natureza. O possível é exatamente como o real, o que lhe falta é a existência. A realização desse possível não é uma criação, já que criar implica em realizar algo novo, algo que não estava previsto. Já o virtual não se opõe ao real, mas sim ao atual. Assim, o que diferencia o possivel do virtual é que no possível já se tem bem claro o que irá acontecer já se dimensiona todos os acontecimentos que decorrerão sobre algo, e o virtual é um conjunto de possibilidades que complexifica essa realização.

Então, o virtual é um nó de tendências ou de forças que acompanha uma situação, um objeto, uma entidade qualquer, e necessita de um processo de realização para equalizar um possível dentro de todos os que existem. Esse processo de escolha, de realização de um desses vários possíveis que o virtual contém chama-se atualização. Ela aparece como a solução de um problema, uma solução que não estava contida no problema, que necessitava de uma criação. Quando o possível se realiza, ele é atualizado exatamente como o previsto. Porém, para o virtual a atualização funciona como um indexador de possíveis que realiza um dos muitos possíveis que contém o virtual. Por isso Lévy fala que "O atual em nada assemelha-se com o virtual: responde-lhe" (LÉVY. 2007, p. 17). A virtualidade não corresponde a uma desrealização, mas a um deslocamento do centro do objeto a ela apresentado. Ela não vê a solução de um problema como definitiva, ela vê essa solução como uma das soluções dadas a um problema muito maior, ou seja, ela repensa a solução em direção ao problema de maneira geral. Ela desdobra um questionamento previamente estabelecido, explorando ao máximo todos os ângulos de uma questão. Então, o virtual tem a visão de um macro problema, e através das atualizações 


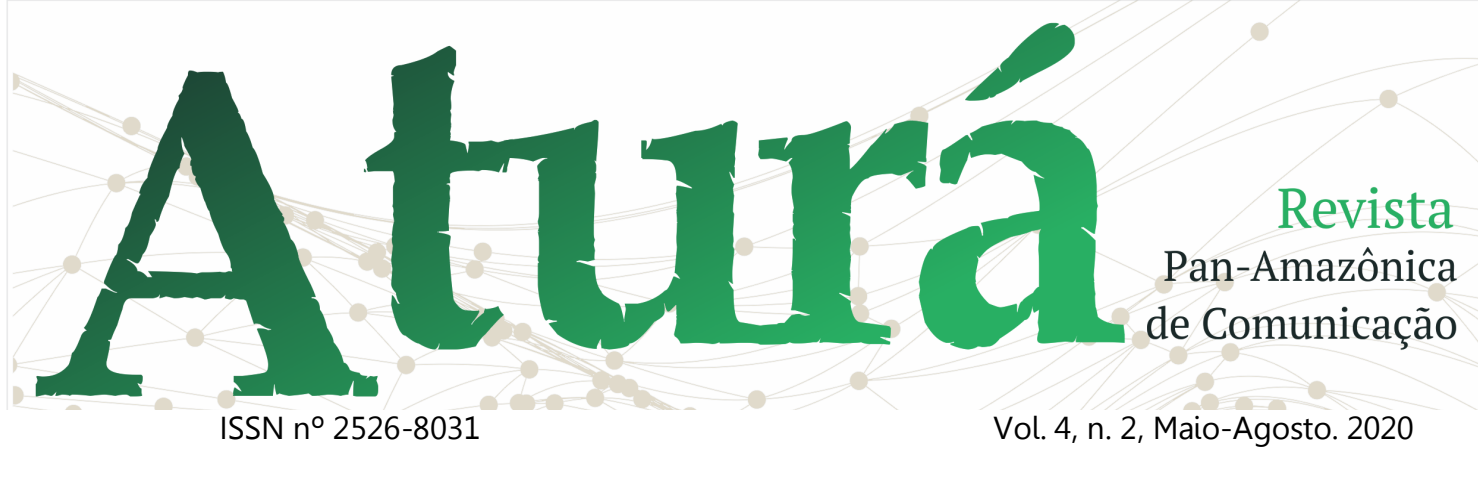

DOI: http://dx.doi.org/10.20873/uft.2526-8031.2020v4n2p242

essas respostas vão se constituindo, para novamente serem virtualizadas. Por isso a atualização/virtualização é um processo cíclico e retro-alimentativo. De modo geral, podemos dizer que virtualizar é ver as atualizações como algumas das respostas que necessitam ser entendidas na busca de compreender um todo.

\section{Virtualização}

Outra característica do virtual, talvez a mais importante, é a capacidade de desprendimento do aqui e agora. Essa capacidade foi amplificada com o advento do ciberespaço. Para exemplificar isto Lévy fala que "um texto pode se apresentar como uma atualização de um hipertexto em um suporte informático" (LÉVY. 2007, p. 19). Então por ser desterritorializado ${ }^{2}$ o hipertexto ${ }^{3}$ está presente por inteiro em

\footnotetext{
${ }^{2}$ Remete a ideia de não ser mais necessária a presença física, territorial, para ter uma unidade de lugar.

3 Entende-se como hipertexto escritura não sequencial, texto que se bifurca. $\mathrm{O}$ hipertexto se apresenta como pequenos compartimentos abertos que se ligam a outros, e estes ainda a outros tantos em possibilidades infinitas de leitura.
}

cada uma de suas versões, suas cópias e de suas projeções. Ele contribui para a produção de atualizações textuais de navegação e leitura. Aprofundando a ideia do despreendimento do aqui agora, Lévy fala sobre o "não estar presente" baseando-se em Michel Serres, e nos lembra que esse abandono de presença não é novo e já se manifesta na sociedade através da imaginação, da memória, do conhecimento e da religião, que agem como vetores de virtualização, nos fazendo abandonar a presença muito antes da informatização e das redes digitais (LÉVY, 2007). Com isso ele faz uma breve discussão sobre o significado da palavra virtual, que no alemão parece nos levar a um entendimento de atualização, enquanto no latim nos leva a um entendimento de virtualização. Tendo posta a discussão acerca do que é o virtual, fazemos agora uma abordagem sobre os diferentes conceitos de comunidade.

\section{Comunidades modernas}




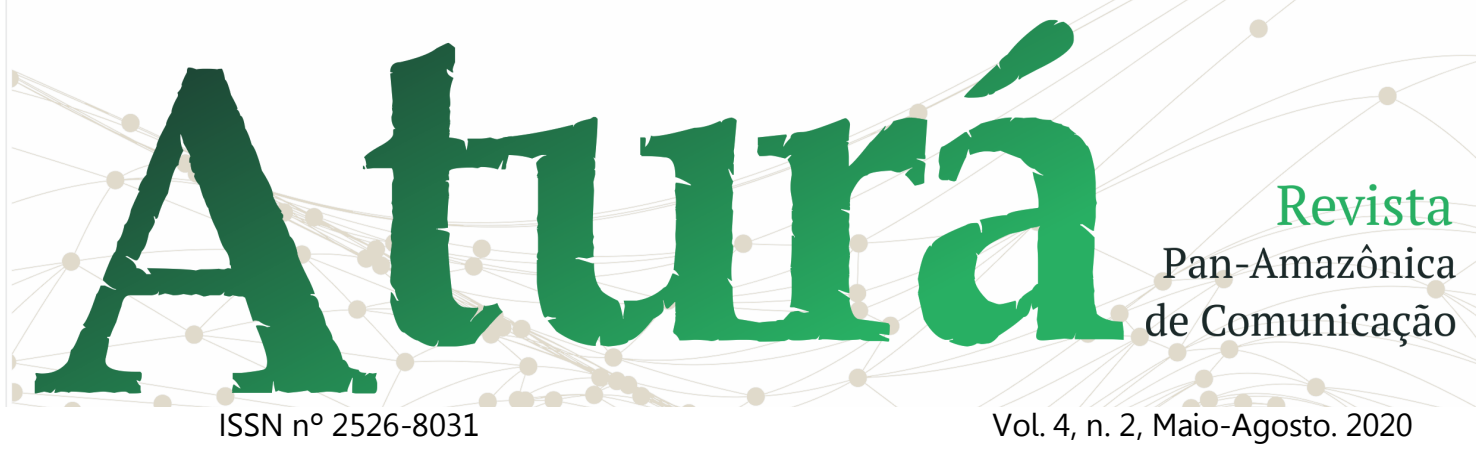

DOI: http://dx.doi.org/10.20873/uft.2526-8031.2020v4n2p242

Ao se falar sobre comunidade, nunca houve um consenso entre os pesquisadores da área sobre um conceito apenas. Cada autor contribuiu de um ângulo específico para conceituá-la. 0 primeiro deles, considerado o pai da sociologia, foi Ferdinand Tönnies. Ele, precursor dos estudos sociais na modernidade, designa o que seria uma comunidade, partindo de um tipo ideal ${ }^{4}$, fazendo uma dicotomia com a sociedade. Mas, segundo o próprio Tönnies a parte mais importante de sua teoria não está na distinção entre comunidade e sociedade, mas sim, no estudo das vontades humanas e através delas é que nascem os conceitos comunitários e societários. Como disse Valério Merlo, leitor de Tönnies, "se a sociedade é uma criação dos indivíduos, segue-se daí que a sociologia não pode fazer menos do que uma teoria da vontade humana" (MERLO, 1995, p. 126). Assim Tönnies divide as

\footnotetext{
${ }^{4} \mathrm{O}$ tipo ideal consiste em escolher somente um caso e livrá-lo das impurezas do mundo observável a fim de encontrar um princípio de acordo com o qual 'funcionaria' em circunstâncias ideais. (TÖTTÖ, 1985, p. 49)
}

vontades humanas tratando da distinção entre vontade biológica e vontade racional e fala:

Toda ação humana caracteriza-se por atos mentais que envolvem 0 pensamento, diferencio a vontade que contém o pensamento, entendida como real e natural, e que denomino wesenwille. $\mathrm{E} \circ$ pensamento que abrange a vontade, compreendida como ideal ou artificial, e que chamarei de kürwille. (TÖNNIES, 1995, p. 273)

A wesenwille é tida como a vontade do homem no seu estado bruto, animal e se manifesta de maneira orgânica, como $\mathrm{o}$ sentimento de preservação, a fome, a reprodução. Ela é imanente ao movimento e à atividade e possui forte carga hereditária.

A kürwille é a vontade do homem enquanto ser isolado, autônomo, e implica na reflexão sobre o desejo. Nela não há impulsão, há uma resposta de reação aos estímulos sociais, onde o humano distingue meios e fins. Por isso, o autor diz que essa vontade não está na comunidade. Partindo dessas distinções é que se constrói a dicotomia entre comunidade e sociedade. 


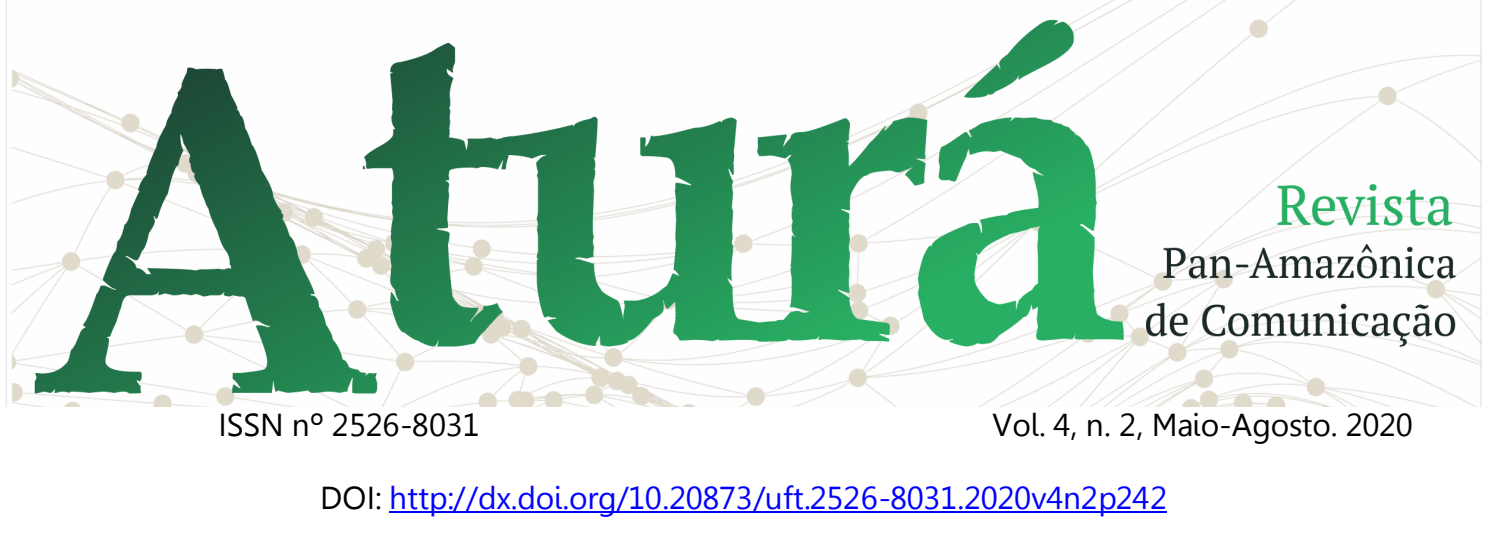

Para ele, a comunidade é um organismo orgânico, real e natural. Nela as pessoas estão unidas de modo natural e reconhecem o espaço em que convivem como parte delas, e há nessa comunidade um sentimento de preservação, de comunhão. Há também um relacionamento de laços fortes, intensos. Como exemplo de comunidade, o autor utiliza a família, um vilarejo, uma aldeia. Assim, no tipo ideal de comunidade de Tönnies não há distinção entre "um" e "outro", já que as pessoas se reconhecem como o "mesmo".

Já a sociedade é um artificial, imaginária e mecânica. Ela nasce com as relações de troca nas relações históricas do capitalismo. Essas relações são artificiais, impulsionadas por uma relação de vontades individuais regidas pela kürwille. $\mathrm{Na}$ sociedade não há um sentimento de pertença, sendo as relações então dadas de maneira individual ou por interesses de quem se está associado. Com isso, cada indivíduo está por si isolado e em um estado de tensão pelos outros (MIRANDA, 1995, p.
65). Também não há relações sociais fortes, ou seja, laços fortes. O que há são apenas relações pontuais que duram somente o tempo que os interlocutores acham necessário para suprir suas necessidades. A sociedade de Tönnies é exemplificada nas metrópoles, no estado, na nação.

Logo após a publicação de Gemenshaft und Geselshaft, Émile Durkhein publica uma resenha crítica sobre a obra de Tönnies, opondo-se à idéia de que somente comunidade teria um caráter orgânico. Para ele a sociedade também é orgânica, ou seja, há organicidade nas duas relações. Ele também fala que são muitas as características que as duas partilham, porém, Durkhein não se opõe à dicotomia de Tönnies.

Para Max Weber, amigo de Tönnies, a comunidade se daria em cima de uma orientação social baseada em uma ligação de cunho emocional. Assim, ele também concorda com Durkhein no sentido de entender que há uma relação entre as características comunitárias e 


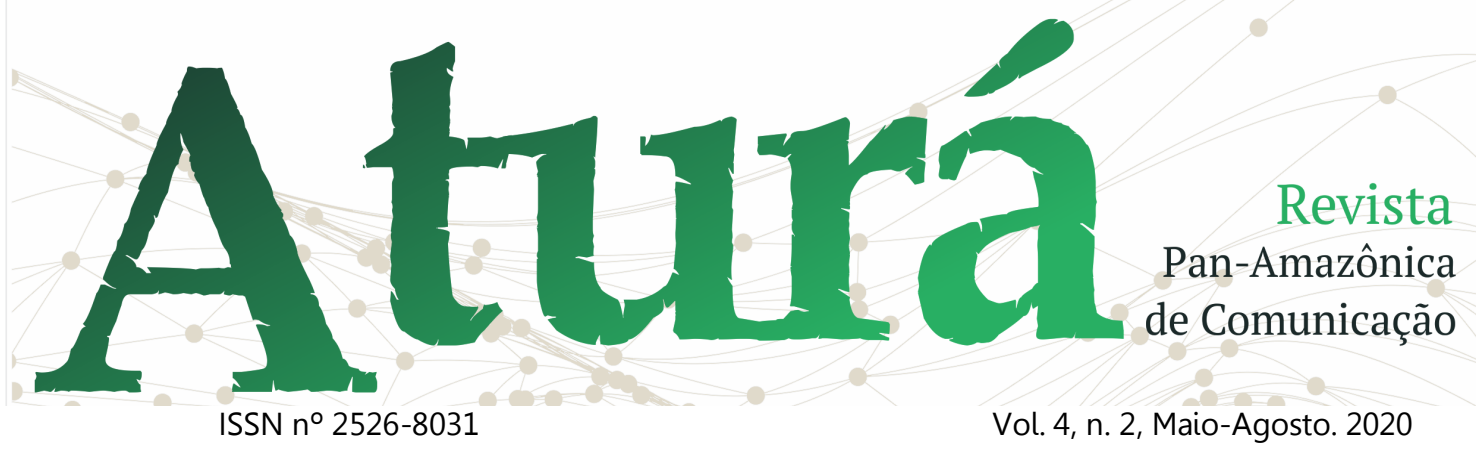

DOI: http://dx.doi.org/10.20873/uft.2526-8031.2020v4n2p242

societárias, principalmente por suas motivações. Para Weber uma comunidade é:

Chamamos de comunidade a uma relação social na medida em que a orientação da ação social, na média ou no tipo ideal baseia-se em um sentido de solidariedade: o resultado de ligações emocionais ou tradicionais dos participantes. (WEBER, 1987, p. 77)

Apesar destes não serem os únicos teóricos a desenvolverem conceitos de comunidade, são os mais estudados, difundidos e influentes estudiosos da modernidade no que diz respeito as conceituações sobre o que seria, de fato, uma comunidade. Assim, pode-se dizer que quase todo trabalho sobre comunidades possui ao menos um desses teóricos como referencial. Depois de expor as ideias sobre o que é comunidade em um pensamento moderno, segue uma breve contextualização de quais as mudanças da sociabilidade na modernidade até termos o que hoje é considerado pósmodernidade.

\section{Modernidade X Pós-Modernidade}

O polonês Zygmunt Bauman trabalha com as mudanças na estrutura social da era moderna até a contemporaneidade. Para ele:

A modernidade substitui a determinação heterônoma da posição social pela autodeterminação compulsiva e obrigatória. Isso vale para a 'individualização' por toda a era moderna - para todos os períodos e todos os setores da sociedade. (BAUMAN, 2001, p. 41)

Assim Bauman, em seu livro Modernidade Líquida (2001), fala que o que houve foi um processo de individualização na sociedade moderna. André Lemos reafirma a fala de Bauman somando a ideia de que na modernidade também houve uma sinergia entre a racionalidade e a emancipação, ocasionando uma administração da vida de maneira racional, e tendo em mente que o homem é um ser auto-suficiente e capaz de se auto-gerir na sociedade. A modernidade faz com que cada pessoa entre num processo constante de individualização, o que acaba interferindo nas relações comunitárias. Essa autosuficiência decorre numa negação da 


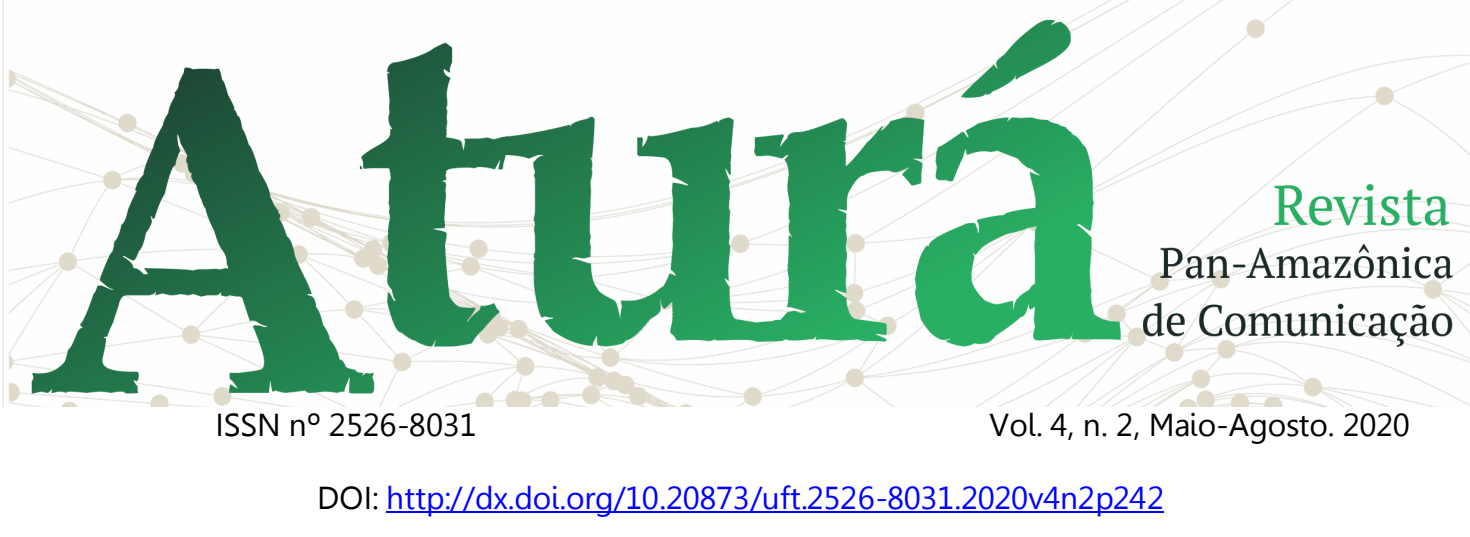

posição heterônoma do indivíduo na sociedade, porque na modernidade "deve-se depreciar todas as tradições, gerando uma transformação da vida social" (LEMOS, 2002, p. 65). Assim, estaríamos vivendo então numa sociedade desagregadora, hedonista, onde os seus membros não se preocupam mais com o todo, e sim, apenas com sua parte. Bauman é o mais ferrenho crítico a essa descomunitarização, que de tão enfático em suas afirmações chega a idealizar a comunidade como um paraíso:

'Comunidade' é nos dias de hoje outro nome do paraíso perdido - mas que esperamos ansiosamente retornar, e assim buscarmos febrilmente os caminhos que podem levar-nos até lá. (BAUMAN, 2003, p. 09)

Claro que Bauman atrela esse sentimento de paraíso a um motivo. Sua ideia de comunidade é baseada na dicotomia segurança-liberdade. Para ele, paga-se tanto um preço de viver em comunidade, que é o de ter obrigações, um cerceamento dos direitos individuais com o intuito de preservar o coletivo. E o de viver em sociedade é a insegurança permanente, o de não ter um caminho seguro para seguir, o de ficar à deriva em meio a uma multidão.

\section{Tecnologias da informação}

Pode-se dizer que as tecnologias da informação surgem com um potencial ambíguo: Coletivo e individualista. Ao mesmo tempo em que o homem inventa a escrita, e possibilita o transporte e a memória do conhecimento para gerações futuras, ele quebra com a necessidade de se estar junto, de se viver e partilhar um conhecimento. Porém, muitos anos mais tarde surgem as tecnologias ligadas à eletrônica (telégrafo, rádio, telefone, cinema) que nascem com uma potência retribalizante (Lemos 2002).

O canadense Marshal McLuhan se dedica aos estudos sobre os impactos que essas tecnologias causam na sociedade. McLuhan fala como esses processos de inovação tecnológica encurtam o espaço geográfico e transformam todo o planeta em uma grande aldeia, numa aldeia global onde 


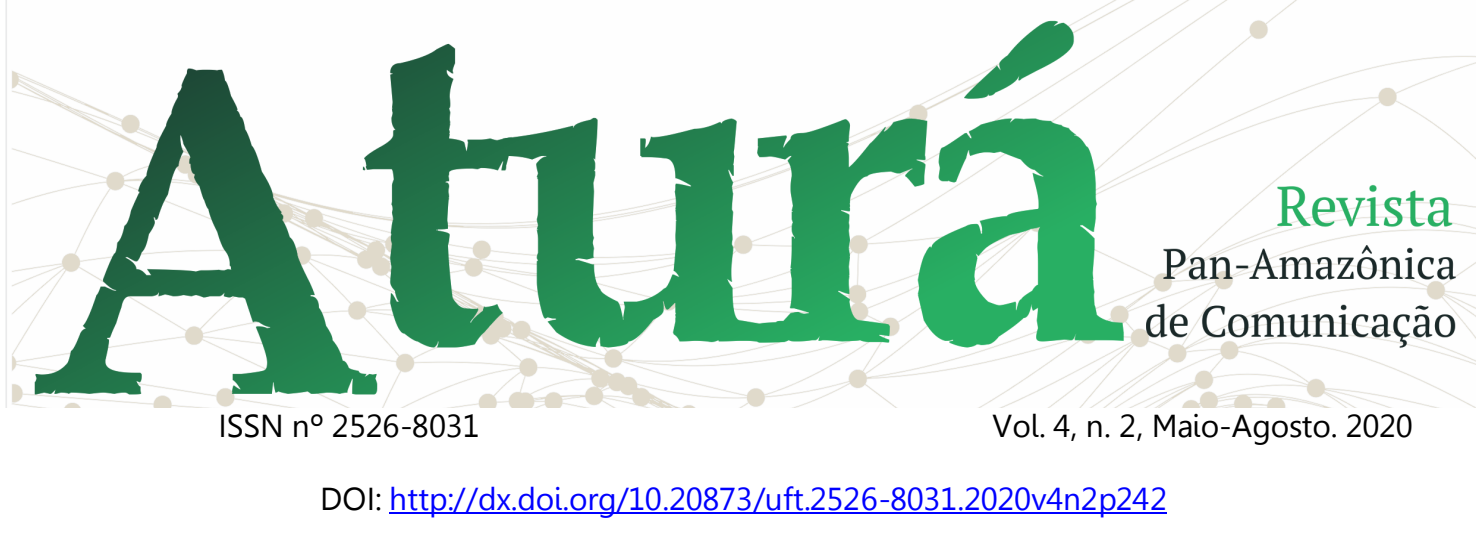

todas as tribos, sejam elas individuais ou coletivas, se encontram. Ao contrário do que alguns teóricos dizem quanto à interferência negativa que as tecnologias possam ter no cotidiano social, McLuhan afirma que essas novas tecnologias não interferem no comportamento humano a ponto de transformar as relações sociais. Para ele "a mensagem de qualquer meio ou tecnologia é a mudança de escala, cadência ou padrão que esse meio ou tecnologia introduz nas coisas humanas" (MCLUHAN, 1964, p. 22), ou seja, as tecnologias não mudam a mensagem nem o contexto das relações sociais, elas apenas prolongam os nossos sentidos e nossas possibilidades. Complementando isso, o autor diz que "quando a tecnologia estende ou prolonga um dos nossos sentidos, a cultura sofre uma transposição tão rápida, quanto rápido for o processo de interiorização da nova tecnologia" (MCLUHAN, 1977, p. 70) Estas citações do autor reforçam duas ideias: A primeira é de que as novas tecnologias podem mudar o formato das mensagens e da sociabilidade, mas não mudam a sua essência. A segunda é de que o homem não começa a criar uma nova personalidade, uma nova cultura totalmente desconexa com a posterior à tecnologia, ao contrário, ele leva toda sua bagagem cultural para dentro do meio em que está se inserindo. Pode-se dizer então que a posição social é heterônoma e não muda de acordo com as novas tecnologias da informação, ela apenas se apropria os novos recursos que essa tecnologia oferece.

\section{Ciberespaço}

Não poderíamos falar de comunidades virtuais sem antes falar sobre o que é afinal o ciberespaço, como surgiu e quais são as principais características desse novo ambiente de sociabilidade que aloca essas comunidades. Como diz Raquel Recuero "o ciberespaço é o espaço onde se desenvolvem as relações que originarão a comunidade virtual" (RECUERO, 2002, p. 17). Então será feito um breve histórico sobre o ciberespaço onde constarão os 


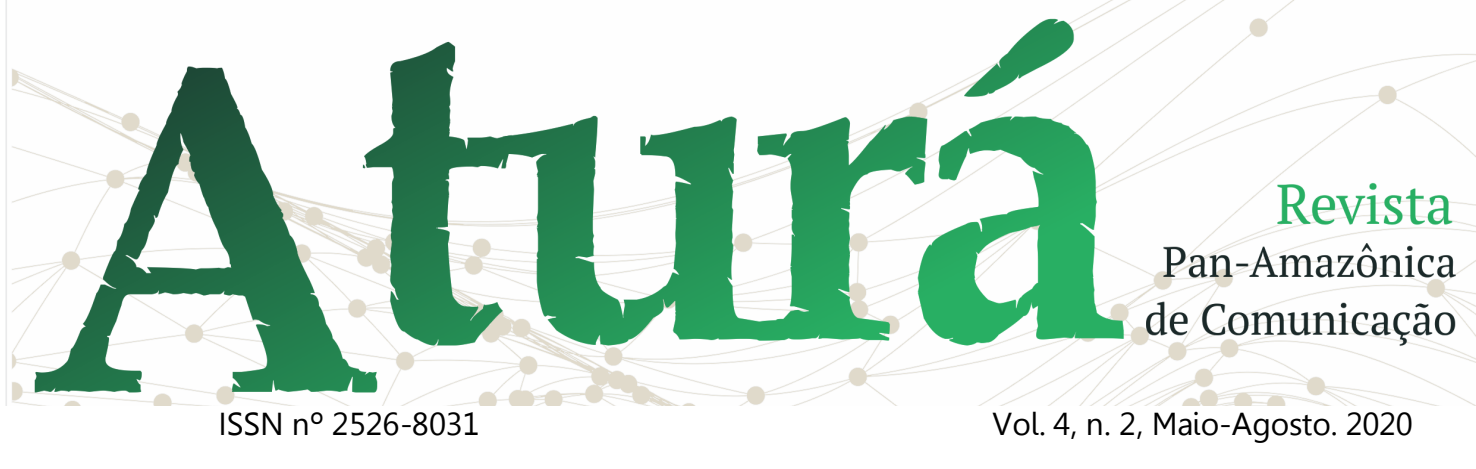

DOI: http://dx.doi.org/10.20873/uft.2526-8031.2020v4n2p242

conceitos dos principais teóricos que trabalham com o assunto.

O termo "cyberspace" foi criado pelo escritor de ficção científica Wilian Gibson para designar o universo das redes digitais. Para Gibson, o ciberespaço consiste num espaço não físico ou territorial composto por um conjunto de redes de computadores através das quais todas as informações, sob todas as formas, circulam. Hoje o termo também é definido por vários teóricos que pesquisam o tema, porém, o ciberespaço é tão amplo que pode ser definido de várias formas dependendo do viés com que é visto, mas, em síntese pode ser definido como o "espaço aberto de comunicação aberto pela interconexão dos computadores e das memórias dos computadores" (LÉVY, 1999, p. 92), ou como sendo "um conjunto de redes de telecomunicações criadas com o processo digital de circulação das informações" (LEMOS, 2002, p. 136). Apesar de alguns pontos de conceituação serem diferentes, todos falam ou remetem a ideia de rede de computadores interconectada por onde passa o fluxo da informação.

\section{Comunidades virtuais}

Pierre Lévy, ao explicar o que é o virtual, levanta uma discussão importante acerca das questões relacionadas às comunidades e como estas se apresentam no ciberespaço:

Uma comunidade virtual pode, por
exemplo, organizar-se sobre uma base de
afinidade por intermédio de sistemas de
comunicação telemáticos. Seus membros
estão reunidos pelos mesmos núcleos de
interesses, pelos mesmos problemas: a
geografia, contingente, não é mais nem
um ponto de partida, nem uma coecção.
Apesar de 'não-presente', essa
comunidade está repleta de paixões e de
projetos, de conflitos e de amizades. Ela
vive sem lugar de referência estável: em
toda parte onde se encontrem seus
membros móveis... ou em parte alguma.
(LÉVY, 2007, p. 20)

A ênfase dada pelo autor, relacionada às comunidades virtuais, parte da análise de que elas são desenvolvidas a partir do interesse comum entre os indivíduos. Mas antes de entrar nas questões mais pontuais sobre - pensamento de Lévy sobre as comunidades virtuais, faz-se necessário 


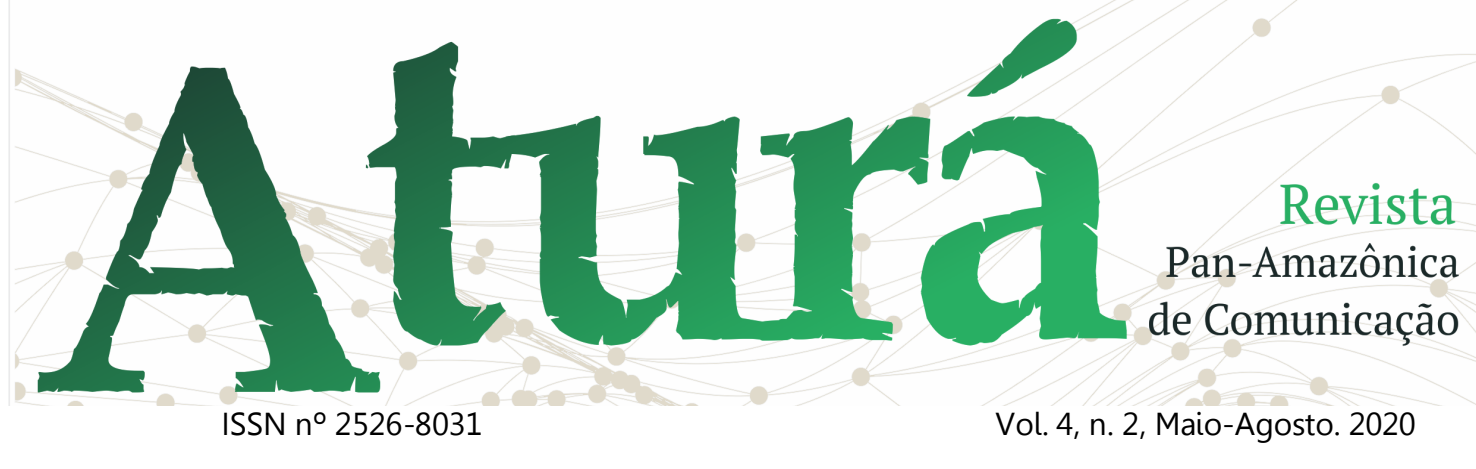

DOI: http://dx.doi.org/10.20873/uft.2526-8031.2020v4n2p242

uma discussão sobre a origem do conceito. $\mathrm{O}$ primeiro autor a utilizar $\mathrm{O}$ termo "comunidade virtual" foi Howard Rheingold, pioneiro que impulsionou as discussões sobre esses novos espaços de sociabilidade. Para ele:

\begin{abstract}
as comunidades virtuais são os agregados sociais surgidos na Rede, quando os intervenientes de um debate - levam por diante um número e sentimento suficientes para formarem teias de relações pessoais no ciberespaço. (RHEINGOLD, 1993, p. 18)
\end{abstract}

Rheingold fala das comunidades virtuais como um espaço em que as pessoas interagem em busca de assuntos de seu interesse, apoiado por um computador conectado a internet. Porém, para a construção de uma comunidade virtual o autor ressalta que não basta somente disponibilizar uma série de ferramentas de interação para os interagentes. É necessário que exista interesses compartilhados, sentimentos comunitários e perenidade nas relações. Ele aponta que a principal vantagem de uma comunidade virtual é a possibilidade do interagente entrar diretamente no assunto desejado através de tópicos armazenados na memória da comunidade, e como a principal desvantagem a falta de contato físico, de impessoalidade. Embora não haja materialidade nas relações 0 autor destaca que "as pessoas das comunidades virtuais fazem tudo o que as pessoas da vida real fazem, mas estão desprendidas de seu corpo" (RHEINGOLD, 1993, p. 16). E é sobre a vantagem à que Rheigold se refere, que se abre um flanco de discussão acerca das comunidades virtuais. Essa discussão será apontada no final do trabalho. Lévy também conceitua comunidade virtual em seu livro "Cibercultura". Para ele:

\begin{abstract}
Uma comunidade virtual é construída sobre as afinidades de interesses, de conhecimentos, sobre os projetos mútuos, em um processo de cooperação ou de troca, tudo isso independentemente das proximidades geográficas e das filiações institucionais. (LÉVY, 2000, p. 127)
\end{abstract}

Ou seja, Lévy fala que o fio condutor de uma comunidade é uma vontade comum a todos. Assim, as comunidades virtuais aparecem no ciberespaço através da junção de pessoas em um espaço determinado, não físico, 


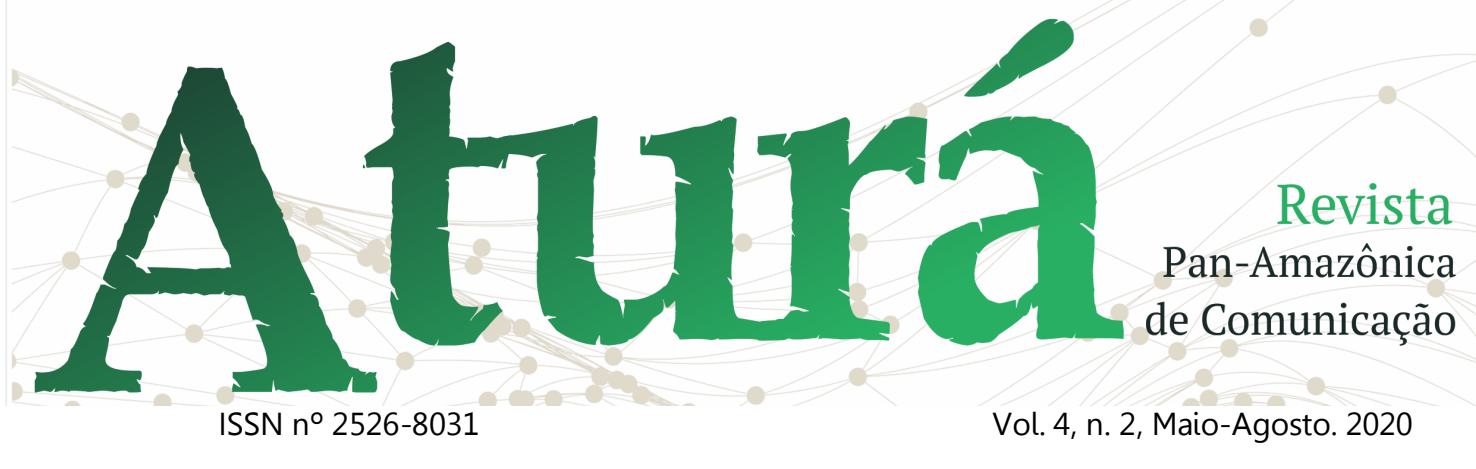

DOI: http://dx.doi.org/10.20873/uft.2526-8031.2020v4n2p242

onde há a possibilidade de integrar pessoas através das interações entre elas. Então, se não há interação, não há comunidade. Outra definição, a partir do estudo sobre o que são comunidades virtuais, é feita por Sanmya Tajra, que define comunidades virtuais como:

Agrupamentos de pessoas que utilizam um ambiente virtual com interesses em comum e mantêm suas conexões vivas, principalmente por meio das relações de interações, colaborações e cooperações que, conseqüentemente, proporcionam novas oportunidades para seus elementos. (2002, p. 38)

Para Tajra, então, o núcleo das comunidades virtuais são as interações entre os integrantes. Assim pode-se interpretar que a comunidade virtual só é viva quando atualizada. Lévy fala que na realidade as "comunidades virtuais" fazem uma atualização de grupos humanos que eram apenas potenciais antes do advento do ciberespaço. Partindo disso, poderíamos dizer que uma comunidade virtual é uma virtualização de uma potência específica e que funciona como uma ferramenta indexadora de vontades específicas, que só se completam, funcionam, quando os integrantes que dela participam têm a possibilidade de agirem entre si. Isso seria o mesmo que dizer que é uma comunidade virtual é um conjunto de possíveis sobre um determinado tema, que não possibilita uma interação mútua entre seus integrantes. A interação entre os participantes seria de ordem indireta e possibilitada pela memória que o ciberespaço fornece como suporte. Assim, a comunidade virtual seria como um grande depósito de ideias, um hipertexto que possibilita para as pessoas a busca de informações muito específicas sobre um assunto muito específico. $\mathrm{Na}$ informática, os computadores nos permitem criar pastas para dividir arquivos específicos. Assim, essas comunidades virtuais teriam muito pouco a ver com o conceito de comunidade clássica, com relações sólidas. Por isso, Lévy fala que:

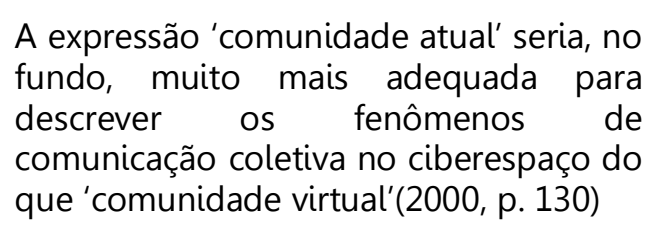

A expressão 'comunidade atual' seria, no fundo, muito mais adequada para comunicação coletiva no ciberespaço do que 'comunidade virtual'(2000, p. 130) 


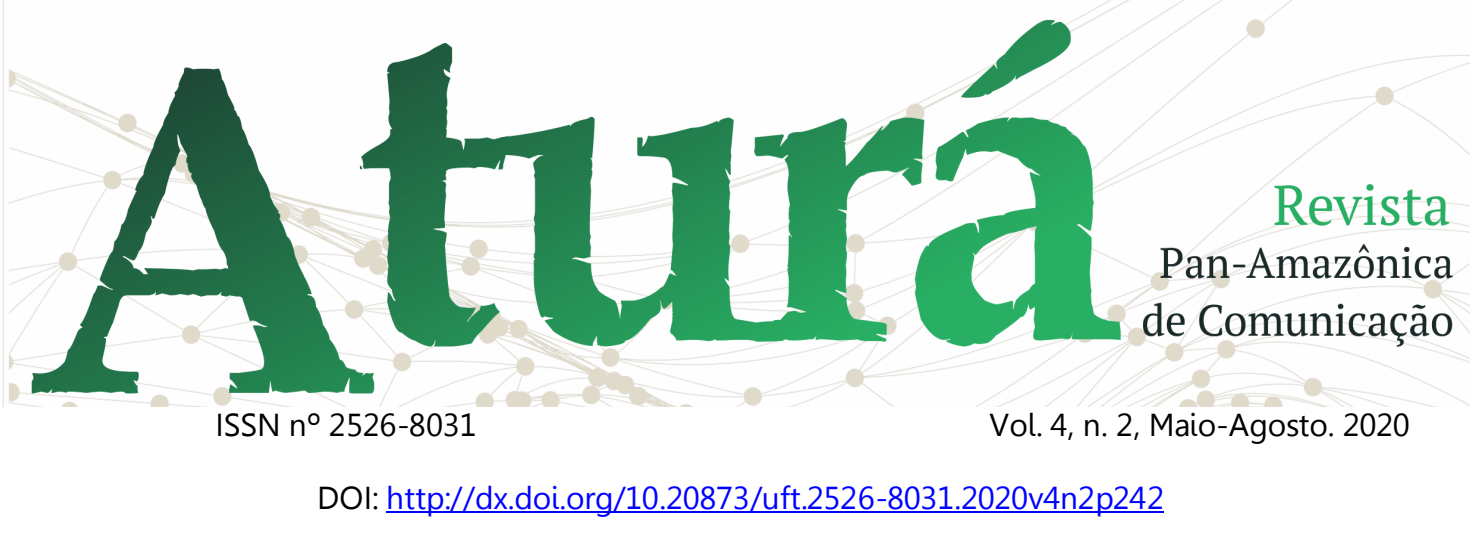

A partir destes conceitos, surgem questões que, de certa forma, nos fazem repensar o que seria de fato uma "comunidade virtual" de outras. Uma delas é a de que estaríamos caindo em erro ao tentar descrever o que é uma comunidade virtual, já que pelo excesso do uso já não se tem mais condições de designar seu significado. Outra seria a de tentar designar algo que, por natureza, não possui condições de ser definido, já que está sempre em processo de transição e qualquer caracterização sobre ela poderia rapidamente perder 0 sentido.

\section{Comunidade virtual X Cibercomunidade}

Como vimos no o decorrer do trabalho, a palavra "comunidade" possui diversas interpretações e significados, o que também acontece com a palavra "virtual". Se elas sozinhas já possuem inúmeras significações e significados, a junção das duas em apenas um entendimento se torna, no mínimo, uma incoerência, já que elas ao invés de "atualizarem" a discussão, "virtualizamna".

Um ponto que fica claro é o de que quando utilizam $\circ$ termo "comunidade virtual" os autores se referem às interações sociais dentro do ciberespaço. Porém, o que chama a atenção é o fato de se usar independentemente da ferramenta (software) que se utilize no ciberespaço um mesmo termo para classificar diferentes maneiras e modos de interagir, denominando todos eles do mesmo modo.

Então, ao falar em "comunidades virtuais" para designar as interações no ciberespaço há uma redundância. Se o ciberespaço é conceituado como sendo uma rede de computadores interconectada por onde passa o fluxo da informação, e nessa rede está contida a possibilidade de se ter infinitas possibilidades, não seria precipitada uma conceituação de algo indimensionável? Será que essas "comunidades virtuais" não podem funcionar como uma construção hipertextual, e assim possuir 


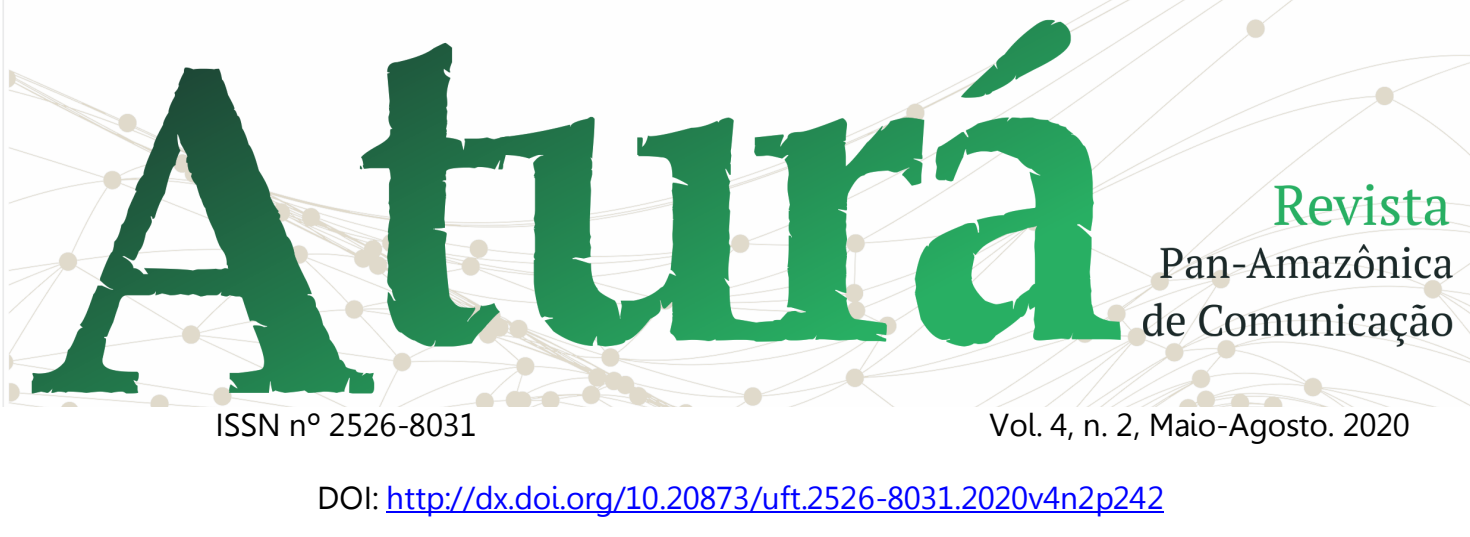

mais um caráter de "lugar de consulta" do que propriamente um local de interação social?

Portanto, a sugestão que se deixa ao final desse trabalho é a de que ao estudar as interações que existem dentro dos grupos alocados no ciberespaço, chamados hoje de "comunidades virtuais", sejam chamados de cibercomunidades. Então, o que defendemos é que o nome "comunidades virtuais" pode ser um dentre diversas interpretações para as interações no ciberespaço, e que o termo "cibercomunidades" parece fazer mais sentido para entender a complexa e imensa gama de componentes que envolvem o estudo sobre o tema das interações sociais no ciberespaço

\section{Considerações finais}

A partir das ideias levantadas e debatidas durante $o$ artigo, pôde-se notar que há uma confusão no entendimento do que é uma comunidade virtual, causada pela utilização comum do termo para designar os locais de interação, ou não, no ciberespaço. Assim, nota-se a necessidade de um melhor entendimento sobre quais são afinal as características dessas "cibercomunidades", antes de se fazer classificações precipitadas sobre elas. Cabe aqui ressaltar também que a proposta de utilização desse novo termo é feita para denominar não apenas as interações, mas as relações como um todo que ocorrem dentro do ciberespaço, contribuindo assim para a discussão acerca do tema.

\section{Referências}

BAUMAN, Zygmunt. Modernidade líquida. Jorge Zahar Editor. Rio de Janeiro, 2001.

LÉVY, Pierre. Cibercultura. Editora 34. São Paulo, 2001

LÉVY, Pierre. O que é o virtual? Editora 34. São Paulo, 2007

LEMOS, André. Cibercultura: Tecnologia e vida social na cultura contemporânea. Editora Sulina. Porto Alegre, 2002.

MERLO, Valério. Rumo à Origem da Sociologia Rural: Vontade Humana e Estrutura Social no Pensamento de Ferdinand Tönnies. In: MIRANDA, Orlando de. Para ler Ferdinand Tönnies. Edusp. São Paulo, 1995. 


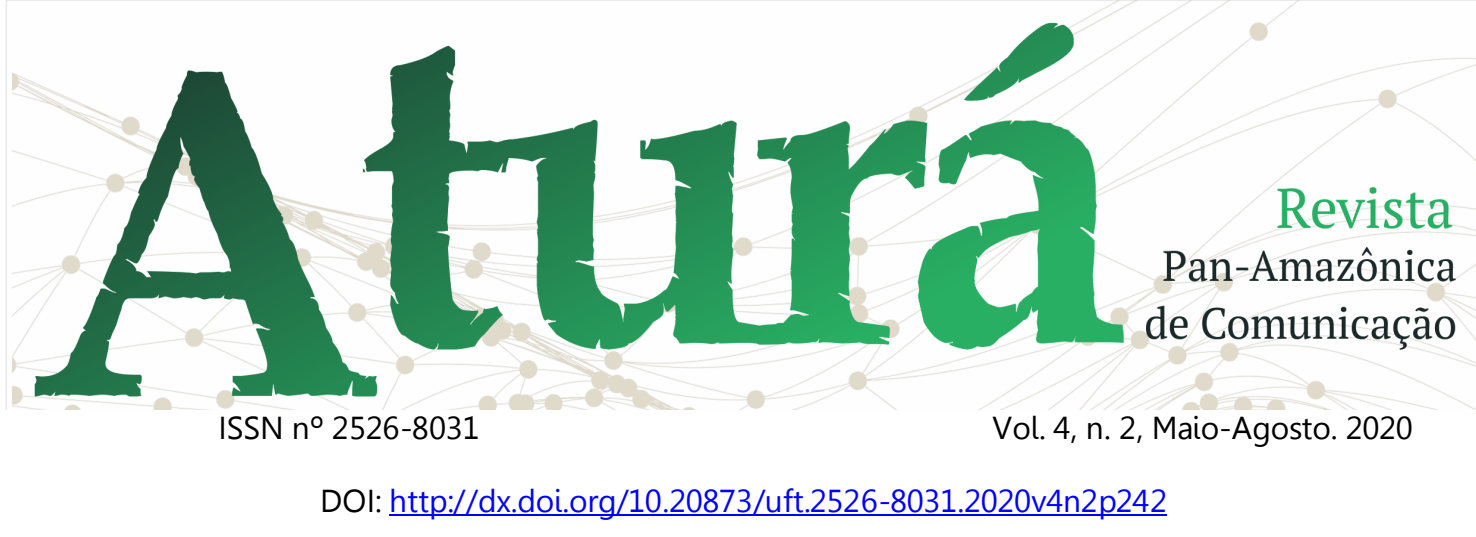

MCLUHAN, Marshall. A galáxia de Gutemberg. Companhia Editora Nacional. São Paulo, 1967.

MCLUHAN, Marshall. Os meios de comunicação como extensões do homem. Editora Cultrix. São Paulo, 2000.

MIRANDA, Orlando de. Para ler Ferdinand Tönnies. Edusp. São Paulo, 1995.

MIRANDA, Orlando de. A Armadilha do Objeto - O Ponto de Partida de Ferdinand Tönnies. In: MIRANDA, Orlando de. Para ler Ferdinand Tönnies. Edusp. São Paulo, 1995.

MIRANDA, Orlando de. A dialética da Identidade em Ferdinand Tönnies. In: MIRANDA, Orlando de. Para ler Ferdinand Tönnies. Edusp. São Paulo, 1995.

RECUERO, Raquel. Comunidades em Redes Sociais na Internet: Proposta de Tipologia baseada no Fotolog.com. Tese de Doutoramento. UFRGS, 2006.

RHEINGOLD, Howard. A comunidade virtual. Editora Gradiva. Lisboa, 1993.

TÖTTÖ, Pertti, Ferdinand Tönnies, um Racionalista Romântico. In: MIRANDA, Orlando de. Para ler Ferdinand Tönnies. Edusp. São Paulo, 1995. 